\title{
Reservoir impacts on water security
}

\author{
ALEKSANDR A. TSKHAI \\ Altai Academy of Economics and Law, 86 Komsomol'sky Av., Barnaul 656038, Russia \\ taa1956@mail.ru
}

\section{INTRODUCTION}

Considerations within the framework of the Panta Rhei Research Initiative of IAHS allow investigation of reservoirs as a factor in water security. The assessment of reservoir impact gives an opportunity to estimate the efficiency of their use from this point of view.

On the one hand, reservoir creation leads to the satisfaction of the needs of society for water. On the other hand, the environmental impact is not always friendly to humans.

The insufficient development of a methodological framework for impact analysis and forecasting hampers the finding of optimal technical solutions, especially for forecasting of reservoir behaviour at the design stage before regulation. Creation of a dam changes the ecosystem characteristics of the regulated part of the river not only quantitatively but qualitatively. In this regard more universal approaches should be used than the traditional statistical analysis of previous data. For example, it is necessary to move from phenomenological water quality models to simulation of nutrient biogeochemical cycles' transformation and calibration should be carried out on the data of a reservoir analogue. These investigations are integrated and interdisciplinary initially. At the same time, outcomes will be more similar to the technology for use in practice.

\section{RUNOFF REGULATION}

Reservoirs are traditionally used for runoff regulation for the needs of power engineering and the water economy, especially during floods and periods of low water. The ecological consequences of different changes outside of the project regime of exploitation for the Novosibirsk Reservoir were forecast and compared (Tskhai and Ageikov 1997).

For best providing the needs of the municipal economy a few water regime scenarios were proposed with the decline of water level near a dam of 1,2 and $3 \mathrm{~m}$ below the level of the dead volume. It was required to estimate the influence of such changes on water quality in the Novosibirsk Reservoir over a year.

For environmental forecasting, the simulation of biogeochemical transformation for nutrient compounds cycles was executed for the aquatic ecosystem of the Novosibirsk Reservoir with description of the external and internal substance streams. Calculations for real regimes of the reservoir's exploitation give an opportunity to verify the aquatic ecosystem model created, called "Biogen".

Prognosis scenario calculations corresponded to suggestions about extra increases of the discharge. The offered variants of regime changes for the Novosibirsk Reservoir in winter were to make it 1-3 m lower than the level of the dead volume, resulting in variation of the average volume and pollutant concentrations, the dynamics of which was simulated. The influence of this factor on the aquatic ecosystem state during the whole year is negligible. It gives an opportunity to formulate conclusions about the implementation of sanitary-hygienic norms of water quality should the exploitation offer regimes for the Novosibirsk Reservoir be implemented.

Later this Biogen was used to provide ecological expertise for designing projects for a few Siberian and Far-Eastern reservoirs creation.

\section{EUTROPHICATION MINIMIZATION}

During exploitation of thermal power, cooling of the hydroelectric turbines takes place in the special reservoir-cooler. As result of the high temperature influence, the process of eutrophication 
develops intensively in a reservoir. Warm water with bio-flow enters the river. As a result the eutrophication process is disseminated through the river downstream.

Eutrophication simulation for three project variants of the placing of parts of the thermal power station was executed for the Uryup River (Tskhai et al. 1998). For model calibration, observation data were used from Lake Balaton which corresponded to the period of its intensive eutrophication. The investigations allowed selection of the optimal project variant and elaboration of its exploitation regime with minimum distribution of eutrophication consequences to the river downstream.

\section{POLLUTION DESILTER}

Reservoirs are widely used in industrial agglomerations is as desilters for pollution. The river flow velocity is slowed within the reservoir. As a result, suspended river sediment - and sorbed contaminants - settle to the bottom. Thus the river stream becomes less turbid.

However this water "purification" is often only partial. As a result of resuspension and convective-diffusive release, secondary pollution of the reservoir appears from the bottom. In the reservoir, biocoenosis processes increase as compared to a natural river ecosystem. This is accompanied by the accumulation of toxic substances in the trophic chains of aquatic organisms.

For environmental forecasting of the consequences of reservoir creation in similar cases it is important to simulate the annual dynamics of the contents and substances streams in all components of the ecosystem. Such research was executed for the project variants of the Krapivino Reservoir exploitation for different hydrological years (partly published in Tskhai and Ageikov 1994).

The simulations conducted show that the behaviour of aquatic ecosystems associated with the design variants of exploitation for the yet to be constructed Krapivino Reservoir, and of the existing Novosibirsk Reservoir, will not substantially differ from the point of view of ecological safety.

\section{RESEARCH DEVELOPMENT}

Today it seems that the actual problems of water security are in the connection between hydrological changes and human health consequences, i.e. in human ecology. But sustainability problems for hydrological, environmental and social systems are on the agenda. For the future, our main investigation direction is the dynamic search for balances of these systems.

Acknowledgements The present work was partially developed within the framework of the Panta Rhei Research Initiative of the International Association of Hydrological Sciences (IAHS).

\section{REFERENCES}

Tskhai, A.A. and Ageikov, V. Yu. (1994) Simulation of nutrient transformation in a reservoir ecosystem. In: Peters, N.E. et al. (eds) Hydrological, Chemical and Biological Processes of Transformation and Transport of Contaminants in Aquatic Environments. IAHS Publ. 219, 303-308.

Tskhai, A.A. and Ageikov, V. Yu.. (1997) Mathematical modeling of transformation processes for nitrogen and phosphorus compounds and oxygen regime changes in reservoirs. Water Resources 24(6), 664-674.

Tskhai. A.A.. Veriovkin. M.N. and Solodky, O.G. (1998) Hvdroinformatics methods for water quality assessment in river basin. In: Babovic and Larsen (eds) Hydroinformatics'98. Rotterdam, Balkema, 1273-1280. 